\title{
The Revision of Japan's National Guidelines for Care and Education at Day Nursery and Its Problems
}

\author{
Takeo Shishido \\ Aichi Prefectural University \\ Japan
}

\begin{abstract}
This article is written to introduce the main contents of the revised National Guidelines for Care and Education at Day Nursery (henceforth New Guidelines), which were recently announced by the Ministry of Health, Labor and Welfare (MHLW), and the challenges associated with these New Guidelines. The National Guidelines for Care and Education at Day Nursery is the national curriculum for Japan's day nurseries, an official educational institution for preschools and kindergartens under the authority of the Ministry of Education, Culture, Sports, Science and Technology (MECST). The New Guidelines are the fourth revised edition of such a curriculum. Unlike the previously issued guidelines, the New Guidelines, which were publicly announced by the Minister of Health, Labor and Welfare, are legally binding as a minimum standard for child care and education. This article is focused on introducing (a) roles of day nurseries, (b) child care and education, (c) promotion of food education, (d) plans and evaluations of child care and education, and (e) transition from preschool to elementary school. Some additional points worthy of consideration, such as minimum standards for day nurseries, plans and self-evaluation of child care and education, problems of child care and education plans, and parental involvement are also included in this article. It is recommended the New Guidelines not be regarded as being faultless. Rather, positive efforts should be made based on the practices and studies of child care and education to improve the Guidelines in accordance with social trends.
\end{abstract}

Key words: day nursery, child care and education, National Guidelines for Care and Education at Day Nursery

Japan's Early Childhood Care and Education (ECCE) system is a dual parallel system composed of kindergartens and day nurseries. ${ }^{1}$ Under the School Education Law and Child Welfare Law of 1947, the Ministry of Education, Culture, Sports, Science and Technology (MECST) has the authority over kindergartens and the Ministry of Health, Labor and

Correspondence concerning this article should be addressed to Takeo Shishido, Professor Emeritus, Department of Childhood Education at Aichi Prefectural University, Aichi Prefecture Nagakute-tyo 0561-64-1111, Japan, Electronic mail may be sent to shishido@cac-net.ne.jp
Welfare (MHLW) over day nurseries. In addition, the national curriculum for kindergartens (the Course of Study for Kindergarten) and for day nurseries (National Guidelines for Care and Education at Day Nursery) has been independently developed by each respective authority.

Since the National Guidelines for Care and Education at Day Nursery were first devised in 1965, they were revised in 1990 and 1999 (henceforth, Old Guidelines). In March 2008, the fourth revised edition of the National Guidelines, that will be referred to as New Guidelines, were publicly announced by the 
Minister of Health, Labor and Welfare, with plans to begin implementation in April 2009. This article is written to introduce the main contents of the New Guidelines and several additional points worthy of consideration. Day nurseries' childcare curriculum is supposed to evolve in accordance with social developments. The overview of Japan's childcare system and its problems will be offered so that readers can develop a clear idea of how to enhance the childcare system based on the practices and studies of child care and education.

\section{Background on Reasons for Revision of Japan's National Guidelines for Care and Education at Day Nursery}

The National Guidelines for Care and Education at Day Nursery were first devised in 1965 and revised in 1990 and 1999. The fourth revision of the guidelines was issued in 2008. The Guidelines have been revised based on social transformations and evolving practices in early childhood care and education and the New Guidelines were greatly affected by those social factors.

For the past seven years since the third revision, children have had less social interactions within their families and communities and have been enjoying a less structured lifestyle. This has resulted in changes in the childcare environment, where an increasing number of parents and guardians are struggling in their limited child-rearing ability due to their isolation from the national childcare system and insufficient understanding of children. The changing childcare environment has created more expectations for the roles and functions of day nurseries.

Since parents' child rearing capacity is decreasing, quality care and education at day nurseries is critically important to support positive early development for children.. The inclusion of early-childhood education provisions in the Fundamental Law of Education, which was enacted in December 2006, shows how important it is to reinforce education for preschoolers.

Day nurseries have more responsibility for caring and educating the children who are under their care and are charged with providing appropriate support for families with young children while considering the balance between work and family and the relationship between parents and children.

Against this social backdrop, Japan's day nurseries are expected to play their proper roles through care and education for children and support for parents and guardians. There has been demand for improving and reinforcing the National Guidelines for Care and Education at Day Nursery to enhance the quality of day nurseries' child care and education system. ${ }^{2}$

To summarize, the New Guidelines are focusing on two points: the necessity of reinforcing the functions of education according to the evolving childcare environment and the reexamination of day nurseries' roles such as providing child-rearing support for parents and guardians in their communities.

\section{Summarization of the National Guidelines for Care and Education at Day Nursery}

From their original inception until the present, Japan's National Guidelines for Care and Education at Day Nursery have been used as a guideline instead of being compulsorily implemented as a national curriculum.

Contrary to the previous guidelines, which were announced by the Director of the Children and Families Bureau, the New Guidelines were publicly announced by the Minister of Health, Labor and Welfare. The significance of the difference between the former and latter was explained in the report written by the Revision-Related Examination Body (2007) as follows:

1. The National Guidelines for Care and Education at Day Nursery are now publicly announced by the Minister of Health, Labor and Welfare for the purpose of enhancing the quality of day nurseries' child care and education system. It is clarified that 
the Guidelines are the minimum standards for day nurseries' childcare and management system.

2. By being publicly announced, the Guidelines have become the minimum standards to be observed by all day nurseries. However, the contents of the Guidelines should be summarized so that each day nursery's creative efforts to enhance the quality of child care and education system can be promoted. (pp.1-2)

As mentioned above, the Guidelines have become the minimum standards all day nurseries should abide by. According to Article 45 of the Child Welfare Law, the Minister of Health, Labor and Welfare should set minimum standards, and child welfare facility operators should abide by the minimum standards. Under the law, the New Guidelines have become legally binding as the minimum standards to be observed.

Accordingly, the contents of the Old Guidelines (A5/74 pages), which were reminiscent of reference books, were concisely summarized in the legallybinding New Guidelines (A5/22 pages). Unlike the Old Guidelines, where 'the contents' of child care and education were explained by age group (38 pages: less than six month-, 6 15 month-, 15 month 2 year-, 2 year-, 3 year-, 4 year-, 5 year-, and 6 year-olds), the New Guidelines summarize the contents of child care and education for children of all ages in one chapter (7 pages). The Revision-Related Examination Body (2007) explains this in its report as follows:

The National Guidelines for Care and Education at Day Nursery present 'the contents' of child care and education for 8 different age groups from less than six month- to less than 6 year-olds. To promote the summarization of contents, however, it is recommended that the New Guidelines present specific considerations for infants, less than three-year olds, and over three-year olds in addition to common features found in all different age groups. (p. 3)

As mentioned above, 'the contents of child care and education' by age were summarized to a great extent. ${ }^{3}$ In contrast, the part of 'support for parents and guardians' was elaborated in one whole chapter signifying that it has become more important than before.

Table 1.

Chapters and Contents of the New Guidelines

\begin{tabular}{|c|c|c|}
\hline Chapter number & Chapter title & Chapter contents \\
\hline Chapter I & General Provisions & $\begin{array}{l}\text { objectives, day nurseries' roles, principles of child care and education, } \\
\text { social responsibility for child care and education }\end{array}$ \\
\hline Chapter II & Development of Children & $\begin{array}{l}\text { developmental characteristics of infancy and early childhood, } \\
\text { developmental process by age }\end{array}$ \\
\hline Chapter III & $\begin{array}{l}\text { Contents of Child Care and } \\
\text { Education }\end{array}$ & $\begin{array}{l}\text { purposes and contents of child care, purposes and contents of education, } \\
\text { special points to be considered in child care and education }\end{array}$ \\
\hline Chapter IV & $\begin{array}{l}\text { Plans and Evaluations of } \\
\text { Child Care and Education }\end{array}$ & self-evaluation of the plans and contents of child care and education \\
\hline Chapter V & Health and Safety & $\begin{array}{l}\text { support for children's health, environmental \& hygiene management, } \\
\text { promotion of food education, health \& safety implementation system }\end{array}$ \\
\hline Chapter VI & $\begin{array}{l}\text { Support for Parents and } \\
\text { Guardians }\end{array}$ & $\begin{array}{l}\text { basic requirements/supports for the parents and guardians whose } \\
\text { children are under the care of day nurseries, community support for } \\
\text { childcare }\end{array}$ \\
\hline Chapter VII & $\begin{array}{l}\text { Teachers' Quality } \\
\text { Improvement }\end{array}$ & basic requirement/directors' obligation, in-service training of teachers \\
\hline
\end{tabular}


The chapters and contents of the New Guidelines are introduced in Table 1. As shown above, the New Guidelines are composed of 7 chapters. Compared to the Old Guidelines, which comprised 13 chapters (The Contents of Child Care and Education amounting to 8 chapters), the New Guidelines were summarized to a great extent.

\section{Major Changes}

\section{Day Nurseries' Roles}

According to the Old Guidelines, the main role of day nurseries is to support the community childcare system. Day nurseries are required to play social roles such as providing advice on the care and education of infants and young children. Unlike the Old Guidelines, the New Guidelines clarify support for parents and guardians as a core role for day nurseries.

Day nurseries, which are in charge of child care and education, promote connections between a variety of social resources within families and communities and provide support for the parents and guardians whose children are under the care of day nurseries and for the families within their communities (Chapter I -2).

The Support for Parents and Guardians provision is elaborated in three sections: (a) the foundation of day nurseries' support for parents and guardians, (b) support for the parents and guardians whose children are under the care of day nurseries, and (c) support for childcare system in the community (Chapter VI).

\section{Child Care and Education}

The New Guidelines elucidate the difference between child care and education. It is clarified in the Contents of Child Care and Education that the integration of child care and education leads to the practices of child care and education. The New Guidelines elaborate on this as follows (RevisionRelated Examination Body, 2007):

The fact that 'child care' and 'education' are integrated in the real childcare environment should be noted. 'Child care' refers to assistance provided by nursery teachers or the relationship between nursery teachers and children, which are critical to the protection of children's lives and promotion of their emotional stability. In addition, 'education' supports children's healthy growth and sound development, and is composed of five different areas: health, human relationship, environment, language, and expression. Together with these five areas, protection of lives and promotion of emotional stability are interconnected and comprehensively developed through children's various plays in their daily lives. (Preface of Chapter III)

As shown above, the Contents of Child Care and Education are explained in two parts: (a) purposes and contents of child care, (b) purposes and contents of education. It is safe to say that unlike the Old Guidelines, which did not take a serious view of child care (it was briefly mentioned as a 'basic requirement'), the New Guidelines shed new light on the importance of child care.

\section{Promotion of Food Education}

The Old Guidelines emphasized the importance of paying more attention to the meals provided by day nurseries by stating in the Health and Safety section that day nurseries should provide diverse food items and menus and keep balanced nutrition in mind. To strengthen the power to lead a healthy eating lifestyle, the New Guidelines put more focus on food education Day nurseries' food education mandate aims to strengthen the power to lead a healthy eating lifestyle, a fundamental condition for healthy life generally. The promotion of food education is to be carried out based on several components.

First, food education plans including meal provision should be established in the child care and education plans and efforts for evaluation and improvement should be made so that appropriate assistance can be provided to infants and young children for their healthy eating lifestyle. 
Second, through experiences, children should have the opportunity to acknowledge food ingredients as nature's gift and to appreciate the efforts made by cooks, and child care and education environments relating to eating lifestyle such as the relationship between children and cooks and the cooking room should be afforded more attention.

Third, appropriate responses should be made to each child depending on his/her physical and mental conditions such as bad condition, food allergies, and disability under the direction and cooperation of parttime doctors or regularly-visited hospitals. A more professional response is anticipated for day nurseries where a nutritionist is working. It is safe to say that concern over children's deteriorating eating lifestyle is expressed in the New Guidelines, which put more emphasis on food education.

\section{Plans and Evaluations of Child Care and Education}

Through self-examination, day nurseries reached a conclusion that there is a lack of organized motivation and effort in terms of improving child care and education plans and teaching plans (Revision-Related Examination Body, 2007).

Regarding day nurseries' child care and education practices and plans, they tend to provide childcare services depending on nursery teachers' capacity and personal characteristics. There is a lack of organized efforts to improve child care and education system such as the efforts to let nursery teachers develop common understanding of childcare guidance and goals and provide well-planned childcare programs, and to evaluate and reexamine childcare practices in implementing child care and education plans and teaching plans. (p. 4)

As shown above, the New Guidelines aim to strengthen child care and education plans. The 'child care and education plans', which have been adopted so far, have been changed to 'child care and education process'. In addition, 'child care and education process' and 'teaching plans' have been integrated as the 'plans of child care and education'. Since 'child care and education plans' can be confused with the 'child care and education plans' devised by administrative districts, the term 'child care and education process' was born to clarify that multiple plans exist in day nurseries and 'the process' should be at the core of the 'plans of child care and education'. The 'child care and education process' is the equivalent of 'education process', which is adopted in the Course of Study for Kindergarten. In other words, the 'child care and education process' is the curriculum for child care and education. The New Guidelines elaborate on this as follows (Ministry of Health, Labor and Welfare, 2008):

To achieve the goals of child care and education presented in Chapter I (General Provisions), day nurseries should devise 'child care and education process', a fundamental element for child care and detailed 'teaching plans'. The 'child care and education process' and 'teaching plans (plans of child care and education)' should contain flexible, evolutionary, and consistent considerations for children so that they can live a stable life and conduct meaningful activities while being under the care of day nurseries. In addition, day nurseries should care and educate children based on the 'plans of child care and education' and make efforts to evaluate and improve the contents of child care and education. They should also promote quality childcare system and fulfill their social obligation (Preface of Chapter IV).

The 'child care and education process' should be organized considering children's development stages presented in Chapter II (Development of Children). Based on each day nursery's childcare policy and goals, the process should be arranged in a way that the purposes and contents mentioned in the previous chapter (Contents of Child Care and Education) can be comprehensively developed (Chapter IV-1). 
As shown above, the 'child care and education process', a basic element of 'child care and education plans', should be necessarily arranged by day nurseries under the New Guidelines and be subject to evaluation. It is emphasized that the quality of the child care and education system should be enhanced through the arrangement, implementation, and evaluation of the child care and education process, through which the system can fulfill its social obligation. The self-evaluation of the contents of child care and education has been added in the New Guidelines.

The Guidelines explain self-evaluation of individuals (including nursery teachers) and selfevaluation of day nurseries as follows: (a) Nursery teachers should reflect on their practices of child care and education based on childcare plans and records and make efforts to enhance their professionalism and childcare practices through self-evaluation; (b) To enhance the quality of child care and education system, day nurseries should self-evaluate their childcare practices based on the development of childcare plans and nursery teachers' self-evaluation and make the results public. Self-evaluation should be made based on 'the plans of child care and education' (child care and education process and teaching plans) and each day nursery's self-evaluation should be made public. The goal of strengthening efforts on 'the plans of child care and education', which have been pointed out to be insufficient, is clarified.

\section{Transition from Preschool to Elementary School}

So far, day nurseries have been child welfare facilities not educational institutions. Previously, the transition from preschool to elementary school was not considered seriously on the grounds that the two are under the authority of different jurisdictions. However, the New Guidelines clearly stated that the transition from preschool to elementary school will be actively promoted. The Guidelines elaborate on this as follows (Ministry of Health, Labor and Welfare, 2008): (a) Considering that day nurseries' child care and education system is closely linked to daily lives and learning after elementary school, day nurseries should help infants and young children develop creative thinking and autonomy by guiding them to live a lifestyle suitable for their ages; (b) Based on children's lifestyle and continuation of development, day nurseries should contemplate the contents of child care and education and promote the transition from preschool to elementary school by encouraging exchanges (between day nurseries' children and elementary school students and between both institutions' teachers), information sharing, and mutual understanding; and (c) as for information sharing on children, when children under the care of a day nursery enter elementary school, data in support of each child's development should be transferred from day nursery to elementary school so that children can get administrative support.

As mentioned above, much thought should be given to the contents of child care and education based on the continuation of daily lives and learning after elementary school. Also, exchanges and mutual understanding of teachers in day nurseries and elementary schools are required, and data should be transferred to elementary schools in to enable continuity of support for children's development. ${ }^{4}$

\section{The Problems of the New Guidelines}

\section{What Are the Minimum Standards for Day}

\section{Nurseries?}

As described in the report of the Revision-Related Examination Body, the New Guidelines are the minimum standards for day nurseries' contents of child care, education, and childcare-related management.

The previous minimum standards for day nurseries were stated in the Minimum Standards for Child Welfare Facilities. ${ }^{5}$ It stipulated the minimum standards for day nurseries as child welfare facilities and mainly mentioned hardware-sided standards such as physical 
facility standards, arrangement of teachers, ideal hours for childcare, contents of child care and education, and contact with parents and guardians. On top of this, the New Guidelines added softwaresided minimum standards. As the two are like two wagon wheels on the same axle, they should go together to enhance the quality of child care and education.

As for food education, for example, the New Guidelines stated, "A more professional response is anticipated for day nurseries where a nutritionist is working." Although it is desirable for day nurseries to have nutritionists at hand, the current Minimum Standards for Child Welfare Facilities does not acknowledge the necessity of having nutritionists since it stipulated only that, "Day nurseries should employ nursery teachers, part-time doctors and cooks" (Article 33). Thus, the revision of the Minimum Standards for Child Welfare Facilities is strongly recommended at the present time in order to strengthen nutritional education.

The same can be said for 'support for parents and guardians'. In fact, many day nurseries barely provide enough care and education for children, indicating a need to hire more teachers to handle the shortage. If the support for parents and guardians provision is to be implemented under the New Guidelines, day nurseries will need to employ special teachers or counselors to fulfill their newly assigned responsibility. Moreover, they will have to renew and improve their existing facilities, such as counseling centers or child-rearing support centers. Without taking these measures, support for parents and guardians will never be realized and may end up as a meaningless pledge, or it will heavily depend on overworking nursery teachers.

As illustrated above, the New Guidelines may turn out to be no more than empty promises unless followup measures are appropriately taken. The launch of the New Guidelines is expected to serve as an opportunity to take a closer look at and improve the conditions of the child care and education system.

\section{Child Care and Education Plan and Self-Evaluation}

The second issue is the 'plans of child care and education' (child care and education process and teaching plans) and self-evaluation. According to the report on the revision of the New Guidelines by the Revision-Related Examination Body (2007), it is expected that the child care and education process and the process-based teaching plans will motivate teachers to reflect on their child care and education practices, evaluate themselves, and improve their capacity. To build on the child care and education process, teaching plans, and teachers' self-evaluation, day nurseries should make efforts to listen to the opinions of parents and local community residents, do self-evaluations and make the evaluation results public. This is intended to enable day nurseries to enhance the quality of child care and education system and fulfill their social obligation. In particular, the report by the Revision-Related Examination Body states that all day nurseries are required to promote teachers' understanding on their own challenges, using self-evaluation results to the best effect. In addition, the level of the entire staff's teaching quality and specialization must be enhanced through systematic training programs and self-studies. Moreover, the director's responsibility should be clearly defined so that the quality of child care and education provided by teachers can be improved. All of the above stipulations are about teachers' selfevaluation on child care and education effectiveness in accordance with the plans of child care and education. The plans aim to improve the quality of individual teachers as well as that of child care and education.

The plans, however, have two problems, explained as follows. The first problem concerns the inherent characteristics of the plans of child care and education. They are not absolute but hypothetic plans. The plans are devised not by a specific individual but by a group of nursery teachers who are equally involved in the formation, revision, and evaluation of the plans. This process allows child care and education practices to develop more creatively. On the other hand, self- 
evaluation is personal and subjective, and it is not powerful enough to start massive changes desired in the plans of child care and education. Furthermore, self-evaluation stifles creativity of the practices of child care and education by exaggerating the plans of child care and education as faultless, and prevents the plans from becoming scientifically valid through the practices of child care and education.

The second problem is that self-evaluation may threaten the collectivity of the practices. Since selfevaluation is subjective by nature, child care and education practices based on the collectively-devised plans of child care and education should be evaluated by group discussions. What makes the practices complicated is that they are inseparable from teachers' views on children and teaching methodology, and often depends on the overall conditions for child care and education, a hardware-sided issue. Also, the practices reflect children's home environments as well as the human relationships around them, including the level of trust between their parents and teachers. For these reasons, problems should be addressed in a more comprehensive manner. If problems are left unresolved and no clear solution is suggested, selfevaluations can never be constructive. In this sense, mutual evaluations or evaluations that involve group discussions seem more appropriate than individual self-evaluations. As mentioned above, therefore, there are two major problems of self-evaluation. Accordingly, more in-depth discussions on self-evaluation are required.

\section{Inherent Problems of the 'Child Care and Education Plans'}

In the previous section, the child care and education plans are defined as a hypothesis. Like the Old Guidelines, the New Guidelines reveal serious problems when it comes to the child care and education plans. The problems, which will be highlighted here again, will soon be addressed through the practices of child care and education.

The New Guidelines state the principles of the 'methods of child care and education' as follows (Ministry of Health, Labor and Welfare, 2008): (a) an environment, where children can voluntarily and actively develop relationships with others and children's independent activities and mutuality are valued, should be created. In particular, children should be given a comprehensive care and education that combines play and practical learning so they can meet the particular needs of their age (Chapter I -3); and (b) in order to fulfill detailed objectives, children should be provided with a suitable environment, where their lifestyle and thoughts are respected and their independent activities are encouraged (Chapter IV-1).

Such principles are in line with today's universal childhood education that values children's independent activities and pays attention to creating an environment where children can fulfill their detailed educational objectives. The New Guidelines define the goals of the Contents of Child Care and Education and ways to achieve them in five different areas (health, human relationship, environment, language, and expression) and require that the goals be met. According to the New Guidelines, the Contents of Child Care and Education (clarified in the five areas) are composed of goals and ways to achieve the goals. Goals refer to more specified objectives than the ones explained in the general provisions of Chapter I. For example, the goals are that children should live a stable life at a day nursery, teachers should be responsible for helping them experience productive activities, and children should cultivate certain mind-sets and attitudes. Ways to achieve the goals include how teachers should appropriately respond to children's different lifestyles and what experiences children should have with their surrounding environment with the help of their teachers. The guidelines suggest how to achieve the goals with much emphasis and explain there are two ways to accomplish this. One is to enable children to interact with their surrounding environment with the aid of teachers, and the other is to encourage the 
teachers to devise appropriate teaching methods. Like the Old Guidelines, the New Guidelines aim to promote child care and educational practices that shed light on children's independent activities by creating a better environment for children by introducing administrative seminars. In this regard, the so-called Corner Care and Education is expected to be continuously conducted.

In the meantime, there is a sense of crisis that Corner Care and Education may give children too much free space. Therefore, it is likely that current teaching methods by which teachers conduct class will be maintained. An excerpt from the New Guidelines is in Table 2 (Ministry of Health, Labor and Welfare, 2008).

As seen above, the New Guidelines attach high importance to the independent activities of individual children and recognize the values of peer activities that have collective goals. Just as the New Guidelines stress the need to improve children's lifestyle and educational foundation after elementary school (considerations for children over the age of 3 ), the teacher's role in leading children to a more motivating environment will become even more important.

The issue is how to strike a balance between letting children freely interact with their environment and guiding them to achieve a certain set of goals. These two approaches are, in fact, taken at the same time in many cases. Many Japanese day nurseries have adopted daily programs according to which children are allowed to play freely in the morning and attend classes after 10 o'clock. It is expected that similar programs will be introduced in the future as well. Although many have embraced corner-education that values children's independent activities or free-play methods, some still adhere to the nursery's planned activities and do not give free space for children to be independent.

To address these problems, more in-depth practical studies should be conducted on child care and education theories, particularly child care structure theories, so that child care and education can reap the benefits of both teaching approaches explained above. $^{6}$

Table 2.

Teaching Methods

Teaching Methods

\begin{tabular}{ll}
\hline $\begin{array}{l}\text { Children's development: } \\
\text { Around age five }\end{array}$ & $\begin{array}{l}\text { Children play more with common images than with language, and they increasingly play as } \\
\text { a group to meet collective goals. What is more, they sometimes upgrade their plays and } \\
\text { make their own rules. }\end{array}$ \\
\hline $\begin{array}{l}\text { Children's development: } \\
\text { Around age six }\end{array}$ & $\begin{array}{l}\text { Children value their peer's opinions. They engage in role-playing activities, such as } \\
\text { cooperative plays and pretending plays, and keep playing them until they become satisfied } \\
\text { with their roles. }\end{array}$ \\
\hline Health & Children come across a variety of activities and enjoy them. \\
\hline Human relationship & $\begin{array}{l}\text { Children come to discover their common goals by playing with their peers and to cooperate } \\
\text { with them to meet those goals. }\end{array}$ \\
\hline Environment & $\begin{array}{l}\text { Children take interests in local activities and enjoy taking part in the events in and outside of } \\
\text { their nurseries. }\end{array}$ \\
\hline Language & Children enjoy communicating with their teachers during role-playing games. \\
\hline Expression & Children sing songs, do finger plays and dance to the rhythms with their nursery teachers. \\
\hline Considerations for children & $\begin{array}{l}\text { Teachers should help children realize the importance of abiding by rules and make their } \\
\text { own decisions with the medium of practical learning and play. }\end{array}$ \\
\hline
\end{tabular}




\section{Cooperation with Parents and Guardians}

The following is an example that stresses the need for cooperation between parents and teachers.

In the group of one to two-year-old babies who have not fully developed their language skills, some babies often bite each other. There may be several reasons behind the biting behaviors, and day nurseries are usually to blame for letting them happen. Yet, these accidents are likely to cause conflict between parents of the biter and the bitee and lead to a rift in their relationship.

Day nurseries are dealing with this issue by offering relevant information to parents through a series of informal meetings so that parents can fully understand why the biting happens among children of a particular age, and how day nurseries plan to react and prevent these extraordinary behaviors.

Nshikawa and Iba (2004), who study biting behaviors among young children, pointed out that relationships between parents and teachers, among parents, and among teachers are critical in solving children's biting problems; nothing is more important than forming good relationships among adults and actively exchanging information. Trust, mutual understanding, and cooperation between teachers and parents play a vital role not only in addressing children's biting problems but also in providing quality care and education programs at day nurseries. Although the New Guidelines hardly mention the importance of parental involvement, they mention 'support for parents and guardians' on two pages.

The support for parents and guardians falls under the responsibility of nursery teachers, and teacher's specialized role in supporting child care and education cannot be overemphasized. As stated in the general provisions of Chapter I of the New Guidelines, teachers are required to promote cooperation among themselves to support the parents and guardians whose children are under the care of day nurseries. Teachers are also required to pay close attention to the following responsibilities.

There is no disagreement on the need to improve the level of support to parents and guardians. As stated earlier, day nurseries are expected to strengthen a hardware-sided system that enables support. This leads to the conclusion that cooperative efforts among parents and nursery teachers are necessary as well. Not only in the case of biting problems but in general child care and education, cooperation has something to do with parents' basic attitudes towards their child care and education.

Giving a full support for individual parents and guardians is definitely a crucial matter for nursery teachers. However, what is even more crucial is that teachers think of parents and guardians as their partners, not as visitors to day nurseries, and to share the entire process of child care and education with them. It goes without saying that this relationship is good for children as well.

Deep mutual understanding between nursery teachers and parents at parent-teacher meetings or seminars will allow both of them to keep up with each other's efforts and prevent children from feeling confused. Another example is parental involvement in the nurseries' events. When parents take part in nursery's sporting events and exhibitions and help them be successfully, children feel closer to their parents and teachers can redefine their relationship with parents. In addition, parents can form a closer relationship with each other and eventually deepen their understanding on how to raise their kids better at home.

Documents from many day nurseries confirm the importance of parents' and guardians' role in upgrading the quality of day nurseries' child care and education system. For example, the last paragraph of Children of Red Fruit (Red Fruit Day Nursery's teachers, 1985), a document from Red Fruit Day Nursery located in Kyoto goes as follows:

In today's world where human dignity is frequently not respected, protecting children's happiness requires parents and day nurseries to better understand each other and cooperate. When problems occur, we stick to 
the basic motto of Red Fruit Day Nursery: "One for all and all for one." This motto has been in place since the foundation of Red Fruit Day Nursery. We still have room for improvement, but we pride ourselves on what we have achieved so far. Red Fruit Day Nursery has developed into a day nursery where decent care and education are provided and parents and all teachers join in an effort to fight back social problems. We have no doubt adults' positive life attitudes and their strong bond with each other will influence their children's development for the better. (p. 238)

As seen above, not only children and parents but also local community residents, community organizations, and other available resources can affect day nurseries' activities. Therefore, nursery teachers should realize that they are responsible for forming a close relationship with local communities.

\section{Conclusion}

This article attempts to introduce Japan's newly revised National Guidelines for Care and Education and to express my own views on the guidelines' weaknesses. The New Guidelines are the fourth revised edition, but it is far from being a final set of guidelines. The guidelines will go through further improvements and changes as society advances and the practices and studies of child care and education evolve. Nursery teachers should consult the new guidelines and try to provide child care and education relevant to their real needs. The New Guidelines are not a 'golden rule' but only a 'reference', so it should be updated constantly through day nurseries' research and practical trials that both care about children's life and their future.

\section{References}

Ministry of Health, Labor and Welfare. (2008).
National Guidelines for care and education at day nursery. Tokyo, Japan: Ministry of Health, Labor and Welfare.

Nshikawa, U., \& Iba, M. (2004). How to reexamine child care and education to prevent biting problems. Kyoto, Japan: Kamogawa Syuppan Publishing.

Revision-Related Examination Body. (2007). Report on the revision of the National Guidelines for care and education at day nursery. Tokyo, Japan: Ministry of Health, Labor and Welfare.

Red Fruit Day Nursery's Teachers. (1985). Children of Red Fruit. Kyoto, Japan: Mineruba Publishing.

Shishido, T. (2003). Child care and education plans in support of quality practices-the thoughts of child care and education curriculum. Kyoto, Japan: Kamogawa Syuppn Publishing.

\section{Notes}

1 The establishment of kindergartens and day nurseries dates back to the late 19th century in Japan, but it was not before the Second World War that they began developing in earnest. Under the Child Welfare Law of 1947, day nurseries were officially institutionalized and only working parents could keep their children at nurseries. There were other conditions, including the ones that children should have no one to take care of them at home and they could not stay at nurseries for more than 8 hours. The number of day nurseries has been gradually increasing under the circumstance where the Japanese economy has required a female workforce with children. The total number of licensed nurseries stood at 22,624 as of 2005 and it is continuously on the rise. Meanwhile, kindergartens have developed as a part of school systems under the School Education Law of 1947. As of 2005, there were 13,949 kindergartens in Japan and the number remains stable.

2 Report on the revision of the National Guidelines for Care and Education at Day Nursery was written by the RevisionRelated Examination Body on Dec. 21, 2007.

3 Chapter III (Contents of Child Care and Education) in the guidance newly devised by the examination body is composed of nearly same contents with the 'Course of Study for Kindergarten' (MECST) apart from the part of 'purposes and contents of child care' 
4 Data on children are being transferred from kindergarten to elementary school when they get admission.

5 Ordinance of Ministry of Health, Labor and Welfare, No.63, 1948

6 See 'Child care and education plans in support of quality practices: The thoughts of child care and education curriculum' written by Takeo Shishido, 2003. 